\title{
Unemployment and Crime in US Cities During the Coronavirus Pandemic
}

\author{
Julia P. Schleimer - Veronica A. Pear - Christopher D. McCort • \\ Aaron B. Shev • Alaina De Biasi · Elizabeth Tomsich • Shani Buggs • \\ Hannah S. Laqueur · Garen J. Wintemute
}

Accepted: 10 December 2021 / Published online: 27 January 2022

(C) The New York Academy of Medicine 2022

\begin{abstract}
Unemployment and violence both increased during the coronavirus pandemic in the United States (US), but no studies to our knowledge have examined their association. Using data for 16 US cities from January 2018 to July 2020, we estimated the association between acute changes in unemployment during the coronavirus pandemic and violent and acquisitive crime. We used negative binomial regression models and parametric g-computation to estimate average differences in crime incidents if the highest and lowest levels of unemployment observed in each city had been sustained across the exposure period (March-July 2020), compared with observed unemployment in each city-month. During the pandemic, the percentage of the adult population who were unemployed was 8.1 percentage
\end{abstract}

Supplementary Information The online version contains supplementary material available at https://doi. org/10.1007/s11524-021-00605-3.

J. P. Schleimer $(\bowtie) \cdot$ V. A. Pear · C. D. McCort .

A. B. Shev · A. De Biasi · E. Tomsich · S. Buggs ·

H. S. Laqueur · G. J. Wintemute

Violence Prevention Research Program, Department of Emergency Medicine, University of California, Davis, 2315 Stockton Blvd, Sacramento, CA 95817, USA

e-mail: jpschleimer@ucdavis.edu

J. P. Schleimer · V. A. Pear · C. D. McCort - A. B. Shev ·

A. De Biasi - E. Tomsich - S. Buggs · H. S. Laqueur ·

G. J. Wintemute

California Firearm Violence Research Center, 2315

Stockton Blvd, Sacramento, CA 95817, USA points higher than expected, on average. Increases in unemployment were associated with increases in firearm violence and homicide. For example, we estimated an average increase of 3.3 firearm violence incidents (95\% CI: $-0.2,6.7)$ and 2.0 homicides (95\% CI: $-0.2,3.9)$ per city-month from March to July 2020 if all cities experienced their highest versus observed level of unemployment. There was no association between unemployment and aggravated assault or any acquisitive crime. Findings suggest that the sharp rise in unemployment during the pandemic may have contributed to increases in firearm violence and homicide, but not other crime. Additional research is needed on mechanisms of association, generalizability, and modifying factors.

Keyword Gun violence $\cdot$ Violence $\cdot$ Crime . Unemployment · COVID-19

The coronavirus pandemic and efforts to contain it created an economic crisis [1]. In the United States (US), the economic fallout of the pandemic disproportionately affected communities that already experience greater financial vulnerability, thus contributing to increases in both relative and absolute economic hardship [2]. During this same time, rates of violence surged across the US [3]. Despite suggestion that the two are related in the academic literature [4] and popular press, [5] no empirical studies to our knowledge have examined whether the increase 
in unemployment during the pandemic is associated with the increase in violence.

Economic conditions-including poverty, income inequality, and unemployment-are considered important determinants of violent crime and injury $[6,7]$. Rates of violence are the highest in neighborhoods characterized by concentrated socioeconomic disadvantage and high income inequality [8, 9]. Racial disparities in violence and crime have been previously explained in part by higher rates of unemployment [10] and lower wages [11] among Blacks compared with whites.

The link between economic conditions and violence is complex. For example, poverty structures early childhood environments and exposure to conditions that increase risk for violence, e.g., via poor quality education, youth conduct problems, and neighborhood social disorganization [12]. Individuals who lack access to formal and sustained employment might engage in crime to meet financial needs [13]. Economically motivated crimes may, in turn, involve violence [14]. Economic stressors and income inequality could also increase violence via psychosocial pathways, including negative emotions and diminished social control [15].

In addition to generating income, employment may protect against crime via the creation of prosocial bonds [16] and by limiting the time one has available to engage in criminal activity. Greater income equality and employment might have broad community benefits in the form of neighborhood social capital and access to resources which may prevent violence. [17] During the coronavirus pandemic, for example, community violence prevention programs had to furlough staff; [18] when violence prevention specialists are not working, community violence may increase.

Despite well-established cross-sectional associations between socioeconomic status and violence, and theories linking the two, evidence is mixed as to whether population-level rates of violence are sensitive to changes in economic conditions. [19] Several studies have found associations between worsening economic conditions and financially motivated crimes (e.g., burglary, robbery), but no association with other violent crime. [20, 21]

In this ecological study of large US cities with repeated measures from January 2018 through July 2020, we estimated the association between acute changes in unemployment during the coronavirus pandemic and crime. We aim to provide empirical evidence on the unemployment-violence association during the pandemic, adding to our understanding of what factors likely contributed to the substantial increase in violence in the US in last year. For comparability with prior research, we also examine acquisitive crimes. While the pandemic poses challenges with regard to confounding and generalizability, the abrupt, exogenous change in unemployment may also help separate the association of interest from chronically poor economic conditions and from long-term, potentially bidirectional relationships between the exposure and outcomes, both of which may be limitations of prior studies.

\section{Methods}

\section{Study Sample}

The unit of analysis in this ecological study was the city-month. We selected 16 geographically diverse US cities that made crime data from January 2018 to July 2020 publicly available: Baltimore, MD; Boston, MA; Chicago, IL; Cincinnati, OH; Dallas, TX; Denver, CO; District of Columbia; Kansas City, MO; Los Angeles, CA; Milwaukee, WI; Philadelphia, PA; Phoenix, AZ; Riverside, CA; Sacramento, CA; San Francisco, CA; and Seattle, WA.

Measures and Data

\section{Exposure}

The primary exposure was the estimated monthly difference between observed and expected percent unemployed from March through July 2020 (i.e., "excess" unemployment). Percent unemployed (hereafter "unemployment") is defined as the percentage of the civilian, noninstitutionalized labor force ages 16 and older who are unemployed and actively looking for work. [22] Data were obtained from the Bureau of Labor Statistics, Local Area Unemployment Statistics [22].

We estimated expected unemployment for each city-month with seasonal auto-regressive integrated moving average models [23] fit to training data beginning in January 2015 and ending in February 2020, just before pandemic-related shutdowns more than 
tripled unemployment. [1] We fit models using the Hyndman and Khandakar algorithm [24] and examined residual autocorrelation using the Box-Ljung test [25] with the Benjamini and Hochberg correction [26] for multiple testing. Forecast accuracy was assessed with mean squared error (MSE) computed from time-series cross-validation. [27]

\section{Outcomes}

We examined 7 outcomes: intentional, interpersonal firearm violence (hereafter "firearm violence"), and 6 crimes included in the Federal Bureau of Investigation's (FBI) Uniform Crime Reporting (UCR) Program, Part I offenses (homicide, robbery, aggravated assault, burglary, larceny-theft, and motor vehicle theft). Outcomes were measured as the number of incidents per city-month (incidents may involve multiple victims, but data on numbers of victims were not consistently available).

We measured firearm violence with data from the Gun Violence Archive (GVA), a real-time repository for gun violence incidents compiled from approximately 7,500 news outlets and other public sources. [28] We included incidents of intentional interpersonal violence (i.e., assault and homicide) in which 1 or more shots were fired and 1 or more persons were injured or killed.

Other outcomes were obtained from city open data portals (Supplementary Table 1), and they reflect police-reported crime incidents. Classifications varied somewhat across cities; we coded crimes to maximize comparability and included city fixed effects to account for between-city differences in coding schemes (and all other stable characteristics of cities; see the "Analysis" section).

\section{Covariates}

Covariates hypothesized to confound the association of interest were selected a priori. Covariates included cumulative COVID-19 cases and deaths per population, mobility based on smartphone data (a measure of physical distancing), stay-at-home orders, temperature, precipitation, and expected unemployment (to control for variation in chronic unemployment). We included the log of the population as an offset, using data from the US Census Bureau. [29] See Supplementary Table 2 for information on the data sources.
Analysis

We used parametric g-computation to estimate marginal parameters comparing the average difference per city-month from March to July 2020 in the predicted count of each outcome under two counterfactual exposure scenarios. As opposed to traditional regression estimates, this approach is more useful for conceptualizing how the population burden of crime might change if we intervened on the exposure, e.g., reduced unemployment. [30, 31]

The first parameter describes the average difference in the observed outcome (associated with the observed exposure distribution) and the outcome that would be expected if, contrary to fact, excess unemployment in all months (from March-July 2020) was set to the lowest level observed in each city, March-July 2020. This might correspond to an intervention which lessened the increase in unemployment during the pandemic.

The second parameter describes the average difference in the observed outcome and the outcome that would be expected if excess unemployment in all months (from March to July 2020) was set to the highest level observed in each city, March-July 2020. This might reflect the outcome distribution if unemployment had been unabated. By setting values of excess unemployment to the lowest and highest levels observed in each city, we avoid extrapolating beyond the data.

For each outcome, we specified separate generalized additive models [32] with a negative binomial distribution, log link, and the log of the population as an offset. We used the fitted models to predict outcomes under the counterfactual scenarios, holding all covariates, including population size, at their observed levels. All models included indicators for cities to control for time-invariant characteristics of cities, the exposure period (a pre-post dummy for March 2020 to control for effects of the pandemic common to all cities), overall and city-specific time trends to account for secular change, and the timevarying covariates listed above. We additionally accounted for monthly seasonality with a cyclical cubic spline. [33] All continuous variables that exhibited non-linear relationships with the predicted outcome (on the log scale, from the model including covariates) were modeled with penalized cubic regression splines, as in prior studies. [34] Depending 
on the outcome, these variables included time trends and temperature. Models were fitted in the $\operatorname{mgcv} \mathrm{R}$ package (version 1.8.31) using restricted maximum likelihood estimation. [33]

We calculated 95\% confidence intervals with a bias-corrected accelerated clustered bootstrap with 5000 samples. [35] The bootstrap additionally accounted for uncertainty in estimates of excess unemployment by repeatedly simulating each city's time series and re-estimating expected and excess unemployment, taking into account prediction and random error.

All analyses were done in R version 4.0.0 (R Foundation for Statistical Computing, Vienna, Austria). This study was approved by the University of California, Davis Institutional Review Board.

\section{Additional Analyses}

We conducted 4 additional analyses. First, we explored variation in the association over time by generating monthly estimates, March-July 2020. Second, we calculated city-specific estimates because the average association provided by the main analysis may not correspond well to any individual city. Third, we controlled for measures of racial tension and civil unrest related to police violence and structural racism during the summer of 2020 (see Supplementary Table 2 for data sources). Our measure of protests included both events in support of racial justice and greater police accountability and, separately, events in support of white supremacy, other far-right causes, and the police. We hypothesized that these variables were more likely to mediate than confound our association of interest; we therefore interpreted the estimates as the association between excess unemployment and each outcome explained by other mechanisms. Last, we modeled the outcome as the number of injuries (fatal and nonfatal) from firearm violence (information on number of victims was consistently available only for this outcome).

\section{Sensitivity Analyses}

Due to a data reporting anomaly in Kansas City, MO, from December 2018 through March 2019, the number of crimes in Kansas City for the primary analysis was imputed for this period using seasonal loess decomposition. First, to account for possible imputation error, we excluded Kansas City in a sensitivity analysis. Second, we computed $e$-values, which estimate the degree of unmeasured confounding necessary to entirely explain the observed association (i.e., attenuate it to the null), after accounting for measured confounders. [36] For interpretability and comparability with prior research, we converted parameter estimates to rate ratios and present corresponding $e$-values.

\section{Results}

\section{Descriptive}

On average from March to July 2020, unemployment was 8.1 percentage points higher than expected based on model predictions. There was substantial variability between cities in average excess unemployment, ranging from 4.1 in the District of Columbia to 11.5 in Chicago (Fig. 1; Supplementary Table 3). Excess unemployment also varied within cities over time; within-city standard deviations from March to July ranged from 2.1 in the District of Columbia to 5.9 in Chicago (Supplementary Table 3). MSE of forecast accuracy for expected unemployment was 1.4 on average (interquartile range: 1.2-1.5). Observed unemployment per city-month is shown in Supplementary Fig. 1.

On average, larceny-theft was the most common crime, and homicide was the least common (Table 1). Trends in outcomes diverged during the pandemic: violence (aggravated assault, firearm violence, homicide) and motor vehicle theft increased on average, whereas other acquisitive crimes (larceny-theft, robbery) declined during the pandemic or stayed the same (burglary). The average number of incidents per city from March to July 2020 is in Supplementary Table 4. Supplementary Fig. 2 displays crime rates per city-month.

Association Between Excess Unemployment and Violence and Crime

We found evidence of a possible association between excess unemployment and firearm violence and homicide, with confidence intervals that slightly crossed the null. We estimated an average increase of 3.3 firearm violence incidents $(95 \% \mathrm{CI}:-0.2,6.7)$ and 


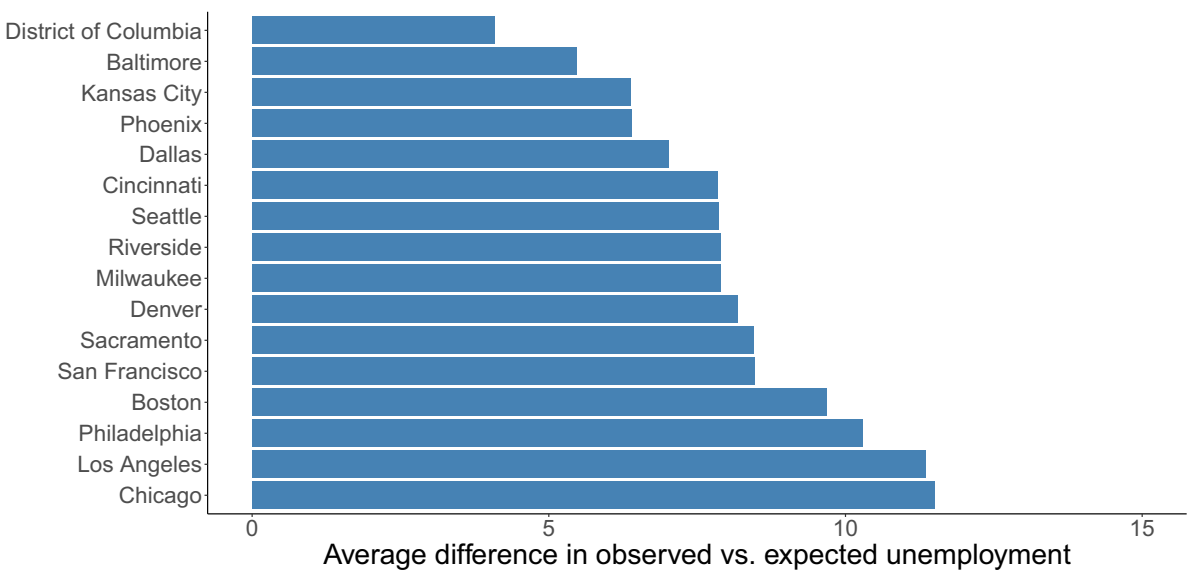

Fig. 1 Average excess percent unemployed by city, MarchJuly 2020. Excess unemployment for each city-month from March to July 2020 is calculated as the difference in observed

Table 1 Monthly rates of violent and acquisitive crime incidents per 100,000 population prior to and during the coronavirus pandemic, 16 US cities ${ }^{\mathrm{a}}$ January 2018-July 2020

\begin{tabular}{lll}
\hline & Pre-pandemic $^{\mathrm{b}}$ & Pandemic $^{\mathrm{c}}$ \\
\hline Violent crime, mean (SD) & & \\
Aggravated assault & $40.7(37.0)$ & $46.4(45.0)$ \\
Interpersonal firearm violence & $3.2(3.3)$ & $4.2(4.3)$ \\
Homicide & $1.2(1.2)$ & $1.7(1.5)$ \\
Acquisitive crime, mean (SD) & & \\
Burglary & $54.7(25.8)$ & $54.5(27.3)$ \\
Larceny-theft & $210.2(93.0)$ & $160.5(55.2)$ \\
Motor vehicle theft & $41.5(20.4)$ & $44.9(21.9)$ \\
Robbery & $24.9(14.8)$ & $19.3(9.7)$ \\
\hline
\end{tabular}

$S D$ standard deviation

${ }^{a}$ Baltimore, MD; Boston, MA; Chicago, IL; Cincinnati, OH; Dallas, TX; Denver, CO; District of Columbia; Kansas City, MO; Los Angeles, CA; Milwaukee, WI; Philadelphia, PA; Phoenix, AZ; Riverside, CA; Sacramento, CA; San Francisco, $\mathrm{CA}$; and Seattle, WA

bJanuary 2018 through February 2020

${ }^{\mathrm{c}}$ March 2020 through July 2020

2.0 homicides (95\% CI: $-0.2,3.9$ ) per city-month if, in every month from March to July 2020, all cities experienced their highest level of excess unemployment versus their observed level in each month (Fig. 2; estimates are also presented in Supplementary Table 5). If all cities experienced their lowest levels of excess unemployment in all months versus their observed level in each month, we estimated unemployment and that predicted by seasonal auto-regressive integrated moving average models

an average decrease of 8.4 firearm violence incidents (95\% CI: - 16.6, 0.8) and 4.5 homicides (95\% CI: $-7.9,0.7)$ per city-month. There was no evidence of an association between excess unemployment and assault or any acquisitive crime (Fig. 3; Supplementary Table 5).

\section{Additional Analyses}

Supplementary Table 6 shows time-varying estimates. Again, excess unemployment was associated with firearm violence and homicide, with confidence intervals that slightly crossed the null. In part because unemployment was lower in March 2020 compared with subsequent months, the associations for high excess unemployment were larger in March than April-July, and the inverse was true of the associations for low excess unemployment.

In Supplementary Tables 7-13, we present city-specific estimates. The associations between unemployment and firearm violence and homicide varied in magnitude and precision across cities (Supplementary Tables 8 and 9). The associations were generally larger in cities with more violence, and we found significant associations (indicated by CIs that did not include the null) in Chicago and Los Angeles for one or both contrasts. As in the main analysis, there was no significant association between excess unemployment and other crime (Supplementary Tables 10-13). 


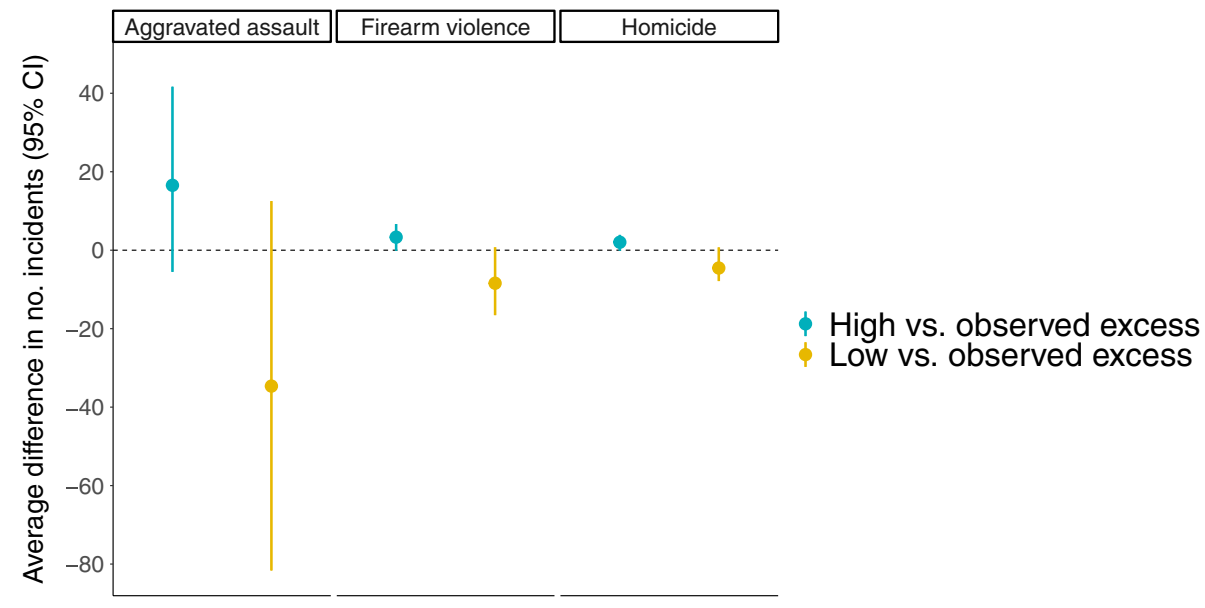

Fig. 2 Adjusted association between excess unemployment and violent crime, 16 US cities (Baltimore, MD; Boston, MA; Chicago, IL; Cincinnati, OH; Dallas, TX; Denver, CO; District of Columbia; Kansas City, MO; Los Angeles, CA; Milwaukee;
WI; Philadelphia, PA; Phoenix, AZ; Riverside, CA; Sacramento, CA; San Francisco, CA; and Seattle, WA) March-July 2020. See Fig. 3 Footnote for description of parameters

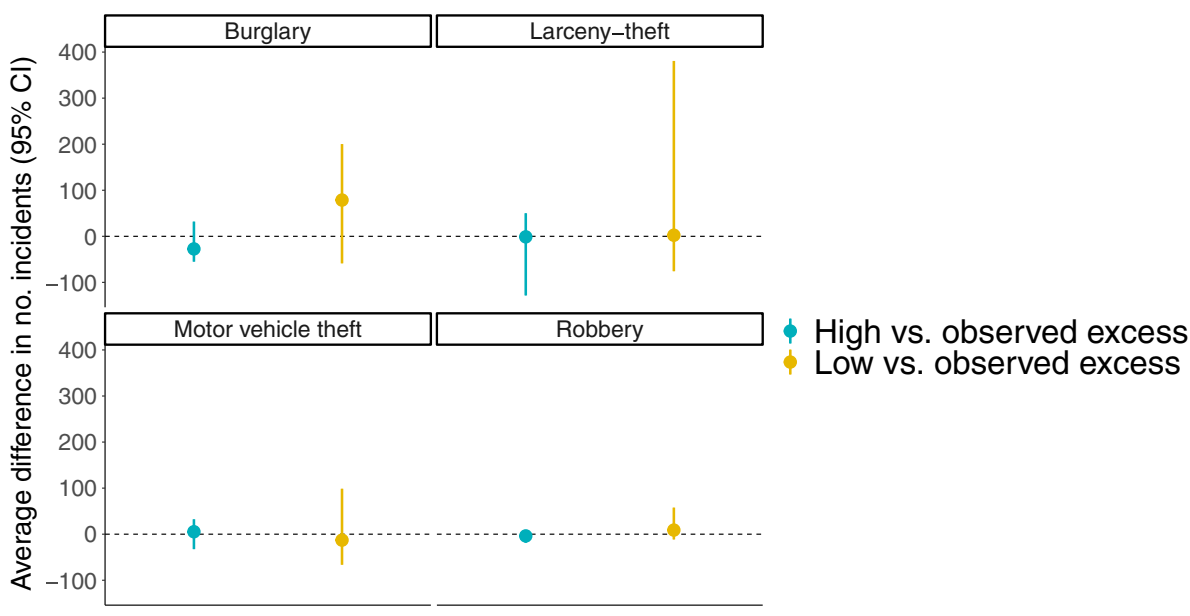

Fig. 3 Adjusted association between excess unemployment and acquisitive crime, 16 US cities (Baltimore, MD; Boston, MA; Chicago, IL; Cincinnati, OH; Dallas, TX; Denver, CO; District of Columbia; Kansas City, MO; Los Angeles, CA; Milwaukee, WI; Philadelphia, PA; Phoenix, AZ; Riverside, CA; Sacramento, CA; San Francisco, CA; and Seattle, WA) March-July 2020. Estimates for the "high vs. observed excess" scenario reflect the average difference in the outcome that would be expected if, for each city, excess unemployment in all months from March to July 2020 was set to the highest

When controlling for police violence at protests against the murder of George Floyd and attendees at level of excess unemployment observed in that city versus the outcome associated with observed levels of excess unemployment in each city-month. Estimates for the "low vs. observed excess" scenario reflect the average difference in the outcome that would be expected if, for each city, excess unemployment in all months from March to July 2020 was set to the lowest level of excess unemployment observed in that city versus the outcome associated with observed levels of excess unemployment in each city-month. No. number, $C I$ confidence interval

protests related to racial justice and policing, estimates were slightly attenuated (Supplementary Table 14). 
Estimates for firearm injuries (not shown) were similar to estimates for firearm incidents.

\section{Sensitivity Analyses}

With Kansas City excluded, results were generally consistent with the main analysis (Supplementary Table 15)

We calculated rate ratios and $e$-values for the 2 outcomes in which there was evidence of an association with unemployment: firearm violence and homicide. We estimated that an unmeasured confounder would need to be associated with both excess unemployment and firearm violence by an RR of 1.4 (high excess unemployment) to 1.7 (low excess unemployment) to entirely explain the associations (Supplementary Table 16). The corresponding estimates for homicide ranged from an RR of 1.5 (high excess unemployment) to 1.9 (low excess unemployment). Confidence intervals already bordered the null.

\section{Discussion}

Results from this study suggest that the sharp rise in unemployment during the coronavirus pandemic may have been associated with an average increase in firearm violence and homicide in 16 large US cities. There was no association between unemployment and aggravated assault or primarily acquisitive crimes: burglary, larceny-theft, motor vehicle theft, and robbery.

We estimated how the population burden of violence and crime might have been different had the highest and lowest levels of unemployment observed in each city been sustained across the entire exposure period (March-July 2020), compared with the observed level of unemployment in each city-month. This approach avoids extrapolating to potentially implausible values (i.e., no excess unemployment during the pandemic) and provides probable worst-case and best-case scenarios in terms of controlling pandemic-related unemployment. We estimated that the highest levels of unemployment sustained across the exposure period were associated with 3.3 more firearm violence incidents (95\% CI $-0.2,6.7)$ and 2.0 more homicides $(-0.2$, 3.9) on average per city over our 5-month period of observation. The lowest levels of unemployment sustained across the exposure period were associated with 8.4 fewer firearm violence incidents (95\% CI - 16.6, 0.8) and 4.5 fewer homicides $(95 \%$ $\mathrm{CI}-7.9,0.7)$ per city-month on average.

Our findings add to the literature on modifiable economic determinants of violence and on the specific factors that may have contributed to an increase in firearm violence and homicide during the first months of the pandemic. While research consistently shows that places with worse economic conditions have higher rates of violence, [8] evidence is mixed as to whether population-level change in economic conditions, including unemployment, affects violence. [19] Studying change, particularly short-term or abrupt change, can help separate the association of interest from confounding by other neighborhood drivers of violence that remain stable over the study period. However, economic shifts at the population level have historically been more gradual, occurring over several months to years. [37] In contrast, some research at the individual level, which has leveraged more acute variation in people's economic status, suggests that job loss increases risk of perpetrating violence, [38] and temporary financial assistance and youth summer jobs reduce it. [39, 40] While our findings cannot inform inferences at the individual level, they are consistent with this prior work.

Our results for both violent and acquisitive crimes differ from prior ecological studies; while prior research has found a positive association between unemployment and acquisitive crime and largely no association for violent crime, [19] we generally found the opposite, though our estimates were somewhat imprecise. Differences between our results and previous research may be due to the context in which the current rise in unemployment occurred. Stay-at-home orders and physical distancing likely increased the guardianship people had over their homes and property and may help explain the absence of an association between unemployment and acquisitive crime during the pandemic. These changes could also help explain the observed relationship with violence. Informal and formal social control were likely weakened during our study period as people stayed home and away from institutions such as work and school. As a result, interpersonal interactions-despite happening with lesser frequency during the pandemicmay have been increasingly violence-prone. 
The nature and context of unemployment may also affect its relationship with violence. Job loss during the coronavirus pandemic disproportionately impacted those in service and hospitality industries; [1] thus, pandemic-related unemployment may reflect a deepening of economic inequality more so than overall economic decline. Income inequality has been linked to increases in violence, including firearm homicide, [9] and may engender a greater sense of injustice and hopelessness than would high—but generally equal-levels of unemployment across population subgroups. [15] Income inequality may also decrease social capital and collective efficacy (i.e., mutual trust, willingness to intervene in conflicts), which are considered key correlates of violence.

The associations for firearm violence and homicide differed from that of aggravated assault. One potential explanation is that increases in firearm purchasing during the pandemic modified the impact of unemployment to increase firearm assaults and homicides more than non-firearm assaults and homicides (data on firearm purchasing in cities are not available for us to empirically test this hypothesis). Firearms are used in approximately $28 \%$ of aggravated assaults [41] but $75 \%$ of homicides nationally. [42] There may have also been underreporting of aggravated assaults, especially considering the tension between police and the wider community during this period.

\section{Limitations}

First, our results may be subject to uncontrolled confounding. For example, substance use and firearm purchasing, which are associated with elevated risk of violence but were not measured at the city level during our study period, both increased during the pandemic. If these factors were positively correlated with unemployment, our estimates would be biased away from the null. However, these variables may also be consequences of unemployment, in which case adjustment would be inappropriate. Our bias analysis showed that an unmeasured confounder would need to have a weak to moderate association (an RR between 1.4 and 1.9) with unemployment and homicide and firearm violence to attenuate the estimates to the null (the lower CIs already included the null). Such confounders are quite plausible, and, though we included all readily measurable and hypothesized confounders, our results should be interpreted accordingly.
Second, there are data limitations. Differential measurement error in estimates of violence could also arise, for example, if higher levels of unemployment in print and other media sectors caused underreporting of firearm violence since the Gun Violence Archive obtains data, in part, from local news outlets. This type of measurement error would, however, result in bias towards the null. In addition, policereported crime data do not capture all incidents (e.g., only $41 \%$ of people who experienced a non-fatal violent victimization in 2019 said they reported it to the police), [43] and the hierarchy rule used to classify crimes results in the reporting of only the most serious crime (e.g., a fatal injury which occurs during a robbery is reported as a homicide). Crime data also varied slightly across cities (e.g., Dallas did not include incidents in which the victim or suspect was under age 17), and unemployment was likely underestimated due to pandemic-related disruptions. [44] Willingness to call the police and report incidents, particularly for less serious offenses, may have decreased during the pandemic; this may help explain declining trends in acquisitive crime and their lack of association with unemployment.

Results from our sample of cities may not generalize to other cities or non-urban areas. We also used data through July 2020 to focus on the abrupt change in unemployment, though the pandemic and its sequelae have continued. We did not test the mechanisms underlying the associations; this is an important area for future work. Lastly, our goal was to quantify the unemployment-crime relationships, and we did not examine whether unemployment benefits or other financial protections buffered against the adverse consequences of unemployment. Future studies should examine such modification.

\section{Conclusion}

Our findings that increases in unemployment may have contributed to a rise in firearm violence and homicide during the pandemic have implications for understanding why violence occurs and how to prevent it. Concentrated socioeconomic disadvantage and income inequality have long been associated with violence, and they are considered key targets of comprehensive violence prevention strategies. Our results indicate that, over and above baseline levels, the acute 
worsening of economic conditions may also increase violence risk. Additional research on this modifiable exposure, including policies and programs that curb increases in unemployment or provide support to the unemployed, may inform strategies to reduce violence and improve public health.

Funding Support for this research was provided by grants SG-20-42400 from the Joyce Foundation, 2019-1728 from the Heising-Simons Foundation, and the California Firearm Violence Research Center.

\section{References}

1. Pew Research Center. Unemployment rose higher in three months of COVID-19 than it did in two years of the Great Recession. https://www.pewresearch.org/fact-tank/2020/ 06/11/unemployment-rose-higher-in-three-months-ofcovid-19-than-it-did-in-two-years-of-the-great-recession/. Accessed 8 Oct 2020.

2. Moss E, McIntosh K, Edelberg W, Broady K. The Blackwhite wealth gap left Black households more vulnerable. Brookings. Published December 8, 2020. https://www. brookings.edu/blog/up-front/2020/12/08/the-black-whitewealth-gap-left-black-households-more-vulnerable/. Accessed 2 May 2021.

3. Rosenfeld R, Abt T, Lopez E. Pandemic, social unrest, and crime in U.S. cities, 2020 year-end update 2021. https:// online.ucpress.edu/fsr/article/33/1-2/72/115493/Pande mic-Social-Unrest-and-Crime-in-U-S-Cities. Accessed 4 Feb 2021.

4. Beard JH, Jacoby SF, Maher Z, et al. Changes in shooting incidence in Philadelphia, Pennsylvania, between March and November 2020. JAMA. Published online February 10, 2021. https://doi.org/10.1001/jama.2021.1534

5. Bokat-Lindell S. Opinion I What's behind the recent rise in shootings? The New York Times. https://www.nytimes. com/2020/08/20/opinion/gun-violence-us.html. Published August 20, 2020. Accessed December 11, 2020.

6. Blumstein A, Rivara FP, Rosenfeld R. The rise and decline of homicide - and why. Annu Rev Public Health. 2000;21(1):505-41. https://doi.org/10.1146/annurev.publh ealth.21.1.505.

7. Goin DE, Rudolph KE, Ahern J. Predictors of firearm violence in urban communities: a machine-learning approach. Health Place. 2018;51:61-7. https://doi.org/10. 1016/j.healthplace.2018.02.013.

8. Krieger N, Feldman JM, Waterman PD, Chen JT, Coull BA, Hemenway D. Local residential segregation matters: stronger association of census tract compared to conventional city-level measures with fatal and non-fatal assaults (total and firearm related), using the Index of Concentration at the Extremes (ICE) for racial, economic, and racialized economic segregation, Massachusetts (US), 1995-2010. J Urban
Health. 2017;94(2):244-58. https://doi.org/10.1007/ s11524-016-0116-z.

9. Rowhani-Rahbar A, Quistberg DA, Morgan ER, Hajat A, Rivara FP. Income inequality and firearm homicide in the US: a county-level cohort study. Inj Prev. 2019;25(Suppl 1):i25-30. https://doi.org/10.1136/injur yprev-2018-043080.

10. Sampson RJ. Urban black violence: the effect of male joblessness and family disruption. Am J Sociol. 1987;93(2):348-82.

11. Grogger J. Market wages and youth crime. J Labor Econ. 1998;16(4):756-91. https://doi.org/10.1086/209905.

12. Sharkey P, Besbris M, Friedson M. Poverty and crime. Oxf Handb Poverty Soc. Published online 2017. Accessed October 8, 2020. https://nyuscholars.nyu.edu/en/publi cations/poverty-and-crime

13. Fagan J, Freeman RB. Crime and work. Crime Justice. 1999;25:225-90. https://doi.org/10.1086/449290.

14. Rosenfeld R. Crime is the problem: homicide, acquisitive crime, and economic conditions. J Quant Criminol. 2009;25(3):287-306. https://doi.org/10.1007/ s10940-009-9067-9.

15. Agnew R, Brezina T. General Strain Theory. In: Krohn MD, Hendrix N, Penly Hall G, Lizotte AJ, eds. Handbook on Crime and Deviance. Handbooks of Sociology and Social Research. Springer International Publishing; 2019:145-160. https://doi.org/10.1007/ 978-3-030-20779-3_8

16. Sampson RJ, Laub JH. Crime and deviance over the life course: the salience of adult social bonds. Am Sociol Rev. 1990;55(5):609-27. https://doi.org/10.2307/2095859.

17. Kawachi I, Kennedy BP, Wilkinson RG. Crime: social disorganization and relative deprivation. Soc Sci Med. 1999;48(6):719-31. https://doi.org/10.1016/S02779536(98)00400-6.

18. Chamberlin V. Without reliable funding, violence prevention programs are at risk. WAMU 88.5 American University Radio. https://wamu.org/story/20/08/31/without-relia ble-funding-violence-prevention-programs-are-at-risk/. Published August 31, 2020.

19. Uggen C, Wakefield S. What have we learned from longitudinal studies of work and crime? In: Liberman AM, ed. The Long View of Crime: A Synthesis of Longitudinal Research. Springer; 2008:191-219. https://doi.org/10. 1007/978-0-387-71165-2_6

20. Raphael S, Winter-Ebmer R. Identifying the effect of unemployment on crime. J Law Econ. 2001;44(1):25983. https://doi.org/10.1086/320275.

21. Aaltonen M, Macdonald JM, Martikainen P, Kivivuori J. Examining the generality of the unemployment-crime association. Criminology. 2013;51(3):561-94. https://doi. org/10.1111/1745-9125.12012.

22. U.S. Bureau of Labor Statistics. Local Area Unemployment Statistics: frequently asked questions. Accessed May 12, 2021. https://www.bls.gov/lau/laufaq.htm\#Q01

23. Box GEP, Jenkins GM. Time Series Analysis: Forecasting and Control. Holden-Day; San Francisco, CA. 1970.

24. Hyndman RJ, Khandakar Y. Automatic time series forecasting: the forecast package for R. J Stat Softw. 2008;27(1):1-22. https://doi.org/10.18637/jss.v027.i03 
25. Ljung GM, Box GEP. On a measure of lack of fit in time series models. Biometrika. 1978;65(2):297-303. https:// doi.org/10.1093/biomet/65.2.297.

26. Benjamini Y, Hochberg Y. Controlling the false discovery rate: a practical and powerful approach to multiple testing. J R Stat Soc Ser B Methodol. 1995;57(1):289-300.

27. Hyndman RJ, Athanasopoulous G, Bergmeir C, et al. Forecast: Forecasting Functions for Time Series and Linear Models. R Package.; 2020. URL: http://pkg.robjhyndman.com/forecast. Accessed 1 May 2020.

28. Gun Violence Archive. Accessed September 25, 2020. https://www.gunviolencearchive.org/

29. US Census Bureau. City and Town Population Totals: 2010-2019. The United States Census Bureau. Accessed February 11, 2021. https://www.census.gov/data/tables/ time-series/demo/popest/2010s-total-cities-and-towns. html

30. Ahern J, Hubbard A, Galea S. Estimating the effects of potential public health interventions on population disease burden: a step-by-step illustration of causal inference methods. Am J Epidemiol. 2009;169(9):1140-7. https:// doi.org/10.1093/aje/kwp015.

31. Fleischer NL, Fernald LCH, Hubbard AE. Estimating the potential impacts of intervention from observational data: methods for estimating causal attributable risk in a crosssectional analysis of depressive symptoms in Latin America. J Epidemiol Community Health. 2010;64(01):16-21. https://doi.org/10.1136/jech.2008.085985.

32. Hastie TJ, Tibshirani RJ. Generalized Additive Models. CRC Press; Boca Raton, FL. 1990.

33. Wood S. Mgcv: Mixed GAM Computation Vehicle with Automatic Smoothness Estimation. https://cran.uib.no/ web/packages/mgcv/mgcv.pdf. Accessed 1 Nov 2020.

34. Nandi A, Prescott MR, Cerdá M, Vlahov D, Tardiff KJ, Galea S. Economic conditions and suicide rates in New York City. Am J Epidemiol. 2012;175(6):527-35. https:// doi.org/10.1093/aje/kwr355.

35. Carpenter J, Bithell J. Bootstrap confidence intervals: when, which, what? A practical guide for medical statisticians. Stat Med. 2000;19(9):1141-64. https://doi.org/10.
1002/(SICI)1097-0258(20000515)19:9\%3c1141::AIDSIM479\%3e3.0.CO;2-F.

36. Mathur MB, Ding P, Riddell CA, VanderWeele TJ. Web site and R package for computing E-values. Epidemiology. 2018;29(5):e45. https://doi.org/10.1097/EDE.00000 00000000864.

37. Congressional Research Service. Unemployment Rates During the COVID-19 Pandemic: In Brief. Accessed May 11, 2021. https://fas.org/sgp/crs/misc/R46554.pdf

38. Rege M, Skardhamar T, Telle K, Votruba M. Job displacement and crime: evidence from Norwegian register data. Labour Econ. 2019;61:101761. https://doi.org/10.1016/j. labeco.2019.101761.

39. Heller SB. Summer jobs reduce violence among disadvantaged youth. Science. 2014;346(6214):1219-23. https:// doi.org/10.1126/science.1257809.

40. Palmer C, Phillips DC, Sullivan JX. Does emergency financial assistance reduce crime? $J$ Public Econ. 2019;169:34-51. https://doi.org/10.1016/j.jpubeco.2018. 10.012 .

41. Federal Bureau of Investigation, Criminal Justice Information Services Division. Crime in the U.S. 2019. FBI. Accessed August 1, 2021. https://ucr.fbi.gov/crime-in-theu.s/2019/crime-in-the-u.s.-2019

42. Centers for Disease Control and Prevention. Fatal Injury Data. Web-based Injury Statistics Query and Reporting System (WISQARS). https://www.cdc.gov/injury/wisqa rs/fatal.html. Accessed 1 Aug 2021.

43. Bureau of Justice Statistics. Data Analysis Tools - NCVS Victimization Analysis Tool (NVAT). Accessed August 1, 2021. https://www.bjs.gov/index.cfm?ty $=$ nvat

44. U.S. Bureau of Labor Statistics. Effects of COVID-19 Pandemic on Employment and Unemployment Statistics. Accessed May 12, 2021. https://www.bls.gov/covid19/ effects-of-covid-19-pandemic-on-employment-and-unemp loyment-statistics.htm

Publisher's note Springer Nature remains neutral with regard to jurisdictional claims in published maps and institutional affiliations. 